\title{
A study on College Students' Consumption Behavior in the Background of Mobile Internet
}

\author{
Ruiyao Zhang \\ Macau University of Science and Technology, Macau, 999078
}

Keywords: Media psychology; Mobile Internet; College students; Consumer behavior

\begin{abstract}
People are striding into the mobile Internet era, and smart phone has become the main communication tool for college students. At the same time, it is one of the most dependent, convenient and fashionable way of life. As a result, campus college students are becoming the main force and leader of mobile Internet consumption. Based on the author's learning and practical experience, this paper firstly analyzed the current situation of college students' information consumption behavior in the background of mobile Internet, and then evaluated the impact of consumer behavior; finally, the problem of how to improve the network information consumption behavior of college students was put forward.
\end{abstract}

\section{Introduction}

China Mobile Internet Development Report (2016) shows: in the first half of 2016, the number of mobile Internet users in China's new Internet was 13 million and 10 thousand, accounting for $61.0 \%$. of new Internet users. On the other hand, mobile Internet applications continue to enrich, and work closely with the user's work, life, consumption and entertainment demand, which promotes PC Internet users continually and rapidly to move to the end of penetration. In the first half of 2016, 23 million and 550 thousand of the new mobile Internet users came from the original PC Internet users, which is an increase of 12 million and 20 thousand from the end of 2015. As an important part of mobile Internet users, college students have more mobile consumption, and their consumer behavior characteristics have higher research significance.

\section{Current Situation of Information Consumption Behavior of College Students in the Background of Mobile Internet}

Consumer tools. College Students' network information consumption tools are diverse, including computers, mobile phones, television, books and periodicals, among which mobile phones are the most widely used. Because of the promotion of the Internet environment, the Internet and traditional communications industry, the financial industry and entertainment industry integration make the integration of mobile phones become the most efficient and convenient tool for information consumption. Students can use mobile phones for e-commerce, Internet banking, entertainment, social and other activities. With the popularity of wireless networks, we use mobile phones to surf the Internet at any time and make consumption a reality at any time. This casual and fast way of information consumption that mobile phone brought caters to the preferences of contemporary college students.

Consumption capacity. With the popularity of information consumption tools such as mobile phones and computers, as well as the information search of college students and the improvement of information retrieval ability, the ability of information consumption of college students has been greatly improved. Compared with the traditional way of consuming information through books and newspapers and periodicals, network information consumption also has higher efficiency. Today, college students who live in universities are basically born in late 1990. The students of this generation have caught up with the good times of reform and opening up, and the rapid development of social economy has greatly improved people's living standards. The students don't worry about food and clothing, and there is more time to enjoy life. This provides a good 
foundation for information consumption.

Consumer psychology. College students are purely consumer groups, and they are consumers who do not participate in production. Because of the special circumstances of their environment, the financial resources of most students are supported by their parents. However, Some college students enjoy a high standard of living and make excessive pursuit of brand-name goods with high price and good quality, which differs greatly from their economic level; parents' unconditional aid in money makes college students not aware of the hard-earned money, which causes unnecessary waste. Irrational consumption consciousness will inevitably lead to irrational consumer behavior, and college students will naturally become "the victims of information consumption"; college life is a group life, and students are inevitably involved in material comparisons. It is very easy for the students to trap into the consumption misunderstanding with pursuing the high consumption and hedonism if they can not correctly deal with this psychological comparison.

\section{Evaluation for College Students' Mobile Phone Consumption Behavior in the Background of the Mobile Internet}

Positive evaluation of college students excessive mobile phone consumption behavior. First, it has changed the traditional learning model and has enabled college students' "mobile learning" to be realized. Mobile learning not only has the basic characteristics of traditional learning methods, but also has the characteristics of high mobility, interactivity, immediacy, time fragmentation and so on. With the rapid development of modern information technology, the forms of knowledge and the sources of knowledge are becoming more and more diversified. And the traditional learning model is becoming more and more difficult to meet the needs of modern society. It is necessary to change the traditional learning model. In this process of change, the emergence of smart phones has imperceptibly affected and changed the way of university learning, and they also become more and more interested in the infinite fun and convenience that this learning approach brings to them. Second, it changed the traditional mode of making friends and communication, and improved their interpersonal skills. In the background of mobile Internet, the changes in the mode of making friends and communication of college students are also complete. Before the advent of mobile Internet and smart phones, the dating patterns among college students are often limited by time, geography, age, sex, and so on. However, with the rapid development of mobile Internet, intelligent terminal technology and various chat applications, the social source of emotional satisfaction of college students has greatly expanded. Third, it opened up the vision of college students and broadened the channels for them to acquire knowledge. The rapid development of mobile Internet and the widespread use of mobile phones in college students have gradually made up for the limitations of books in this respect. The immediacy and portability of the mobile Internet and the large amount of network information make the knowledge of college students no longer limited by time and space. On the one hand, it broadened their knowledge level and enriched their knowledge structure. On the other hand, it improved their own abilities and broadened their horizons.

Negative evaluation of excessive mobile phone consumption behavior for college students. First, the excessive pursuit of mobile phone brands and prices easily gives birth to the campus fetishism thought. In recent years, on the one hand, the rapid development of the market economy has promoted the growth of the national economy and the remarkable improvement of people's material living standard. At the same time, it also accelerates the rapid spread of western consumerism trend in our country. These pleasures and extravagant consumption of the wind will lead to the consumption values that focus on themselves and pursue the material enjoyment. College students are still relatively poor in their cognition and cognitive abilities, and they also have the characteristics of poor self-control, curiosity and imitation. Therefore, they are more vulnerable to some undesirable external consumer influence, so as to enter the misunderstanding of mobile phone consumption. Second, it is easy to develop bad study habits and serious phenomena of learning to step on the short cut. Nowadays, we can see the situation where college students bowing their heads and playing with mobile phones in every corner of our university campus. Their good study habits have changed slowly in the course of their dependence on mobile phones. For example, 
students' picking up mobile phones to watch news, novels, and chatting online and playing games in the course of lectures and so on; some students even play mobile phones from the beginning of the class to the end of the class. Thirdly, excessive use of mobile phones is detrimental to the physical and mental health of college students. In the mobile Internet environment, the big websites are full of bad network information, and some unhealthy garbage information will inevitably be harmful to the development of college students' physical and mental health. College students are still in the critical period of their outlook on life and values. Their social experiences and relative experiences are very shallow, and the ability to judge and identify many things is still inadequate. Because of lacking self-control, they tend to be blind in the face of various information and temptations in the network environment. In such a social network environment, they tend to lose themselves, resulting in confusion of values, infirm moral sense and weak ability to distinguish between right and wrong.

\section{Countermeasures for Improving College Students' Network Information Consumption Behavior in the Background of Mobile Internet}

Cultivate college students to enhance their sense of self-management. As the name suggests, self management consciousness is a kind of encouragement and demand to oneself in thought. The emergence of phenomena like too long Internet time, using the mobile phone during the class and over reliance on the Internet among college students are caused by too poor sense of self-management of the college students. Therefore, it is necessary for college students to cultivate themselves in self-management.

Cultivate college students to enhance the concept of reasonable consumption. The consumer group of college students is a group that has not formed a complete consumption concept. We can see that the proportion of college students' demand for various kinds of consumption is not particularly large when they are surveyed. That is to say, college students have excessive consumption and irrational consumption when they are spending. Regardless of their own and the family's economic situation, some students have blind comparisons with others and follow the trend of psychology with too much pursuit of material enjoyment. In order to solve these bad phenomena, we require college students to set up a correct and reasonable consumption concept, rationally control their consumption behavior, and realize that money has not been easy to come by. On these basis, college students should make their own consumption plan appropriately, and make rational consumption.

Help college students to improve their information consumption ability. College students spend part of their time on the Internet for the reason that they are lack of the ability to get the information they want. For this phenomenon, schools can make corresponding and targeted training. In the course of information retrieval, it can add information, identify the aspects of the curriculum system and let students learn these knowledge. This can not only reduce the time spent in information search, but also more accurately find the information needed. After class, we can carry out lectures on improving the ability of information retrieval, and improve students' information consumption ability.

Establish a good information consumption environment for college students. The demand for information of university students has diversified characteristics, but the main thing is to obtain information about learning. Therefore, it is very important for schools to establish a perfect information environment: the school can improve the information environment by setting up a public information service platform and buying a perfect database system. A perfect information environment can help students get the information that they need more quickly and effectively, and also reduce the erosion of bad information in the process of information search. A good information environment will help students to cultivate a healthy moral awareness and improve the quality of network information consumption. 


\section{Summary}

This paper tool the mobile phone consumption behavior of college students as the main object of study. Firstly, it analyzed the current situation of information consumption behavior of college students in the mobile Internet environment, and then evaluated the mobile phone consumption behavior of college students in the background of mobile Internet based on relative knowledge of media psychology. The article finally pointed out that we should start with the following aspects in order to improve the network information consumption behavior of college students in the background of mobile Internet: train college students to enhance their sense of self-management; cultivate college students to enhance the concept of reasonable consumption; help college students to improve their information consumption ability; establish a good information consumption environment for college students.

\section{References}

[1] Yan Zhen. A Study of College Students' Consumption Behavior in Mobile Payment Era[J]. Modern Shopping Mall, 2016, (18): 9-10., [2017-08-18]., DOI:10.14013/j.cnki.scxdh.2016.18.006

[2] Chen Sibo, Li Hourui, Tian Xinmin. The Impact of Mobile Internet on College Students' Consumer Behavior[J]. Zhejiang Academic Journal, 2016, (02): 208-213. [2017-08-18]. DOI:10.16235/j.cnki.33-1005/c.2016.02.027

[3] Yang Bo. Analysis of Consumer Behavior in Mobile Internet Era[J]. Small and Medium-sized Enterprise Management and Technology (The First Publication), 2016, 144. (03): [2017-08-18].

[4] Li Dandan, Wang Mingxiang. A Study of College Students' Social Reading Behavior in the Background of Mobile Internet[J]. News World, 2015, (11): 91-93., [2017-08-18].

[5] Chen Chuanqia. Analysis on 2015 Mobile Platform Consumer Purchasing Behavior[J]. Sound World, Advertising, 2015, (06): 165-166. [2017-08-18].

[6] Tang Jun. Analysis of Influencing Factors of College Students' Consumption Behavior in Mobile Internet Environment[J]. Modern Business, 2015, (03): 266-267. [2017-08-18].

[7] Liu Yunfeng, Hu Hualei. 4G Spawned New Mobile Internet Applications[J]. Information Communication, 2014, (09): 238. [2017-08-18]. 